\title{
Nephrotic syndrome in The Netherlands: a population-based cohort study and a review of the literature
}

\author{
Loubna el Bakkali • Robert Rodrigues Pereira • \\ Dirk J. Kuik • Johannes C. F. Ket • \\ Joanna A. E. van Wijk
}

Received: 29 October 2010 /Revised: 27 February 2011 / Accepted: 28 February 2011 /Published online: 1 May 2011

(C) The Author(s) 2011. This article is published with open access at Springerlink.com

\begin{abstract}
Nephrotic syndrome (NS) is a clinical diagnosis with proteinuria, hypoalbuminaemia and oedema. NS is rare in children, and its incidence in The Netherlands is unknown. The aim of this study was to estimate the incidence of idiopathic NS in the Netherlands. All paediatric patients (age $0-18$ years) with a newly diagnosed NS in the Netherlands were registered by the Dutch Pediatric Surveillance Unit during the years 2003 until 2006, secondary NS was excluded. All paediatricians filled out questionnaires about the first clinical findings of the patients and incidences were calculated. A literature review on incidences of childhood NS was conducted. The incidence of NS in children in the Netherlands in the years 2003 until 2006 was 1.52/ 100, 000 children/ year. The median age at diagnosis was 3.88 years with a mean age of 5.08 years. A significant male:female ratio of 2.04:1 was found. This prospective study of NS in the Netherlands revealed an incidence of 1.52:100, 000 children/year, and is similar to the incidences found all over the world.
\end{abstract}

L. el Bakkali $(\bowtie) \cdot$ J. A. E. van Wijk

Department of Paediatric Nephrology,

VU University Medical Center,

PO Box 7057, 1007 MB, Amsterdam, The Netherlands

e-mail: 1.elbakkali@vumc.nl

R. Rodrigues Pereira

Dutch Paediatric Surveillance Unit,

Leiden, The Netherlands

D. J. Kuik

Department of Epidemiology and Biostatistics,

VU University Medical Center,

Amsterdam, The Netherlands

J. C. F. Ket

Medical Library, VU University,

Amsterdam, The Netherlands
Keywords Children · Epidemiology $\cdot$ Incidence $\cdot$ Nephrotic syndrome $\cdot$ Prospective study $\cdot$ Review of literature

\section{Introduction}

Nephrotic syndrome (NS) is the most common glomerular disorder of childhood. It is defined by proteinuria, hypoalbuminaemia, oedema and hyperlipidaemia [1]. Most $(80 \%)$ children have a minimal-change NS (MCNS). Other diagnoses, which could be the cause of NS, are focal segmental glomerulosclerosis (FSGS), congenital NS (CNS) and NS due to glomerulonephritis or other glomerulopathies. Although NS is relatively rare, it accounts for mortality and considerable morbidity in young children. The prognosis of NS in children correlates with the spectrum of responsiveness to steroid therapy, from steroid-sensitive NS (SSNS) to steroid-resistant NS (SRNS). SRNS is the most common acquired cause of end-stage renal disease (ESRD) in children [2]. The aim of this study was to determine the incidence of NS in The Netherlands. All new cases of NS in The Netherlands of children $0-18$ years of age were prospectively registered from 1 January 2003 till 1 January 2007. The second aim was to compare these results with the incidences of NS described in the literature.

\section{Methods}

Literature search

A literature search was done in February 2009. We searched for articles in PubMed and Embase. Relevant thesaurus terms and/or free-text terms for NS, epidemiol- 
ogy, cohort, retrospective and prospective study types were used. The searches were limited to the age group of $0-$ 18 years and articles written in English, French, German, Dutch or Arabic. Inclusion criteria were all studies on NS that describe the incidence or epidemiology of NS in children 0-18 years in a nationwide or a hospital population.

\section{Study design}

The registry was started by the working group Idiopathic Nephrotic Syndrome, which consists of all paediatric nephrologists in The Netherlands in collaboration with the Dutch Pediatric Surveillance Unit hosted by The Netherlands Institute of Applied Science [Nederlands Signalerings Centrum Kindergeneeskunde (NSCK) at TNO, Leiden]. The NSCK is a voluntary national registry used by paediatricians to report various rare or new paediatric disorders and is one of 13 paediatric surveillance units in the world. Our study includes all children with newly diagnosed NS between 1 January 2003 and 1 January 2007. The case definition was any child $<18$ years with symptoms of NS defined as oedema, proteinuria ( $>3+$ on a dipstick), low serum albumin $(<25 \mathrm{~g} / \mathrm{l})$ and normal renal function (serum creatinine in normal range for age when not volume depleted), without signs of systemic disease or macroscopic haematuria. The study was conducted in The Netherlands. All paediatricians in The Netherlands received a monthly blue card or Web link to an electronic card and were asked to return the card to the NSCK if they had a patient with a newly diagnosed NS. A questionnaire was sent to the registering paediatrician, which had to be returned to the Idiopathic Nephrotic Syndrome Working Group at the VU University Medical Center, where data were analyzed. When the questionnaires were incomplete, secondary phone calls and visits were carried out to try to complete them as far as possible. The coded questionnaires showed only initials, birth date and a part of the postal code. Medical ethical approval was thought not to be necessary due to the anonymous submission of the questionnaires. Informed consent forms were filled in by the parents of the patients. The number of responding paediatricians working in The Netherlands in 2003-2006 was 694 (mean) divided over 96 paediatric practices and eight university centres with a paediatric nephrology department.

\section{Statistical analysis}

The incidence of NS was calculated by relating the number of de novo NS patients to the number of children $<18$ years who were living during the 4 years of registration in the several provinces separately and in The Netherlands as a whole. The population numbers were extracted from the official statistics organ (Statistics Netherlands). These data can be found on the Web site and are freely available. Male: female ratio and median and mean age of the affected children were calculated from the available data. Pearson's chi-square test was used to compare the incidences of the years and the provinces. A $p$ value $<0.05$ was considered to be significant.

\section{Results}

\section{Literature review}

We found 504 abstracts from PubMed and 214 abstracts from Embase; 669 abstracts were left after removing duplicates. Thirty-one appeared to fulfil the inclusion criteria, but after reading the full articles, only nine fulfilled all inclusion criteria. We found three more abstracts (personal enquiry) that were not found in the systematic search. Hodson et al. [3] published the results of a national registry of children with NS in Australia in the annual report of the Australian Paediatric Surveillance Unit, and Bouissou et al. presented a poster about the epidemiology of NS in two French regions at the European Society of Paediatric Nephrology Congress of 1993. Ultimately, nine retrospective and three prospective studies met all inclusion criteria (Table 1).

\section{Registry}

Between January 2003 and December 2006, 300 children were reported. Initially, the response rate of NSCK was 92.8\% (mean of the years 2003-2006) [4], but after first and second reminders and active inquiries, the response rate increased to $96.7 \%$. Of the 300 questionnaires, 69 did not meet the inclusion criteria due to the fact that some patients did not have a newly diagnosed NS during the period of registration $(7.3 \%)$ but had a relapse, and other patients were registered as NS but had another illness (6.0\%). There were $4.3 \%$ duplicate questionnaires. Seven patients $(2.3 \%)$ were diagnosed abroad with NS: six in The Netherlands Antilles (one on Saint Martin and five on Curaçao), and another in India (this child was later adopted to The Netherlands). These patients were not included in the Dutch incidence for that particular year. During the period of enquiry, five $(1.7 \%)$ medical charts could not be found. Finally, four patients $(1.3 \%)$ with CNS were excluded. Ultimately, 231 patients $(77.0 \%)$ met the inclusion criteria.

The calculated annual incidence of NS in The Netherlands in 2003-2006 was 1.52 per 100,000 living children per year. The incidence for each year ranged from 1.32 to 1.77 per 100,000 children per year. The annual incidences did not differ significantly. The distribution of patients in 
Table 1 Results of the literature review on incidences of neprhrotic syndrome (NS) in childhood

\begin{tabular}{|c|c|c|c|c|c|c|}
\hline Source & Study period & Country (area) & $\begin{array}{l}\text { Number of } \\
\text { patients }\end{array}$ & Male:female & Age & $\begin{array}{l}\text { Incidence } \\
\text { (per 100,000/year) }\end{array}$ \\
\hline \multicolumn{7}{|l|}{ Retrospective studies } \\
\hline Elzouki et al. [5] & $1968-1982$ & Benghazi, Libya & 134 & $1.3: 1$ & $\begin{array}{l}12 \text { weeks-14 years } \\
\text { Mean } 5.7(1.5-13)\end{array}$ & 11.6 \\
\hline \multirow[t]{2}{*}{ Feehally et al. [6] } & $1973-1982$ & Leicestershire, UK & 43 & Asian 2.0:1 & $\begin{array}{l}<15 \text { years } \\
\text { Mean age }\end{array}$ & 2.3 \\
\hline & & & & Non-Asian 1.4:1 & $\begin{array}{l}\text { Asian 4,2 } \\
\text { N-Asian } 4.3\end{array}$ & $\begin{array}{l}\text { Asians } 9.4 \\
\text { Non-Asians } 1.3\end{array}$ \\
\hline McKinney et al. [7] & $\begin{array}{l}1 \text { Jan } 1987-31 \\
\text { Dec } 1998\end{array}$ & $\begin{array}{l}\text { Former Yorkshire } \\
\text { Regional Health } \\
\text { Authority, UK }\end{array}$ & 194 & $1.6: 1$ & $\begin{array}{l}0-15 \text { years } \\
\text { Median SSNS } 4.5 \\
\text { SRNS } 6\end{array}$ & 2.3 \\
\hline Schlesinger et al. [8] & 1946- 1961 & Erie county, USA & 86 & $1.96: 1$ & $<16$ years & 2.0 \\
\hline Sharples et al. [9] & $\begin{array}{l}1 \text { Jan } 1979-31 \\
\text { Dec } 1983\end{array}$ & Birmingham, UK & 44 & $1.8: 1$ & $\begin{array}{l}<16 \text { years } \\
\text { Mean age } \\
\text { Asian } 3.4 \\
\text { European } 4.2\end{array}$ & $\begin{array}{l}5.3 \\
\text { Asian } 16.9 \\
\text { European } 2.6 \\
\text { Afro-Caribbean } 3.4\end{array}$ \\
\hline \multirow[t]{2}{*}{ Srivastata et al. [10] } & 1984-1995 & $\begin{array}{c}\text { Metropolitan area of } \\
\text { Kansas City, USA }\end{array}$ & Group A 148 & Group A $1.5: 1$ & $\begin{array}{l}1-16 \text { years } \\
\text { Group A mean } 6.6 \\
\text { Median } 5.0\end{array}$ & $\begin{array}{l}\text { Group B primary } \\
\quad \text { NS } 2.2 \\
\text { Caucasian } 1.8\end{array}$ \\
\hline & & & Group B 86 & Group B 1.46:1 & $\begin{array}{l}\text { Group B } \\
\text { Mean } 7.38 \\
\text { Median } 5.0\end{array}$ & $\begin{array}{l}\text { African American } \\
3.6\end{array}$ \\
\hline Wyatt et al. [11] & $1970-1979$ & $\begin{array}{l}\text { Eastern part of } \\
\text { Kentucky, USA }\end{array}$ & 34 & 2.09:1 & $1-10$ years & 1.8 \\
\hline Zaki et al. [12] & $1981-1985$ & $\begin{array}{l}\text { Farwaniya and Jahra, } \\
\text { Kuwait }\end{array}$ & 55 & $1.75: 1$ & $\begin{array}{l}<12 \text { years } \\
\text { Mean age } 5.3\end{array}$ & $\begin{array}{l}7.2(<10 \text { years }) \\
6.0(<12 \text { years })\end{array}$ \\
\hline Rothenberg et al. [13] & $1949-1953$ & Cleveland, Ohio, USA & $\begin{array}{l}\text { Ohio } 172 \\
\text { Greater } \\
\quad \text { Cleveland } 54\end{array}$ & $1.07: 1$ & $0-9$ years & $\begin{array}{l}\text { Ohio } 2.3 \\
\text { Greater Cleveland } \\
6.9\end{array}$ \\
\hline \multicolumn{7}{|l|}{ Prospective studies } \\
\hline Wong et al. [14] & $\begin{array}{l}1 \text { Jul 2001-1 } \\
\text { Jul } 2004\end{array}$ & New Zealand & 49 & $2.5: 1$ & $\begin{array}{l}3 \text { months- } 15 \text { years } \\
\text { Mean } 6.1 \\
\text { Median } 4.9\end{array}$ & 1.9 \\
\hline Hodson et al. [3] & $\begin{array}{l}\text { Jul 1998- } \\
\text { Dec } 2000\end{array}$ & Australia & 135 & 1.21: 1 & 3 months -15 years & 1.15 \\
\hline $\begin{array}{l}\text { Bouissou et al. } \\
\text { (ESPN 1993) }\end{array}$ & $1985-1992$ & $\begin{array}{l}\text { Midi-Pyrenees and } \\
\text { Auvergne, France }\end{array}$ & NA & $1.57: 1$ & $1-15$ years & 2.1 \\
\hline $\begin{array}{l}\text { El Bakkali et al. } \\
\text { (this study) }\end{array}$ & $2003-2006$ & The Netherlands & 231 & $2.04: 1$ & $\begin{array}{l}\text { 0-18 years } \\
\text { Median } 3.88 \\
\text { Mean } 5.08\end{array}$ & 1.52 \\
\hline
\end{tabular}

SSNS steroid-sensitive NS, SRNS steroid-resistant NS, NA not available, ESPN European Society of Paediatric Nephrology

The Netherlands with its 12 provinces is shown in Fig. 1. This is a chart of the place of residence of all registered patients. There was no statistically significant difference in distrubution within the provinces. This was also corrected for population density in each province.

The Dutch cohort counted 76 girls and 155 boys with newly diagnosed NS. There was a significant difference between the numbers of boys versus girls $(p=0.0005)$. Median age was 3.88 years at admission (mean 5.08 years). One child was younger than 12 months and older than 3 months. One patient died within a few weeks after diagnosis as a result of sepsis and disseminated intravascular coagulation. The mortality rate was 1 of 231 patients $(0.43 \%)$ during the first 5 weeks after presentation. 
Fig. 1 Distribution of patients with a newly diagnosed nephrotic syndrome in The Netherlands during 2003-2006

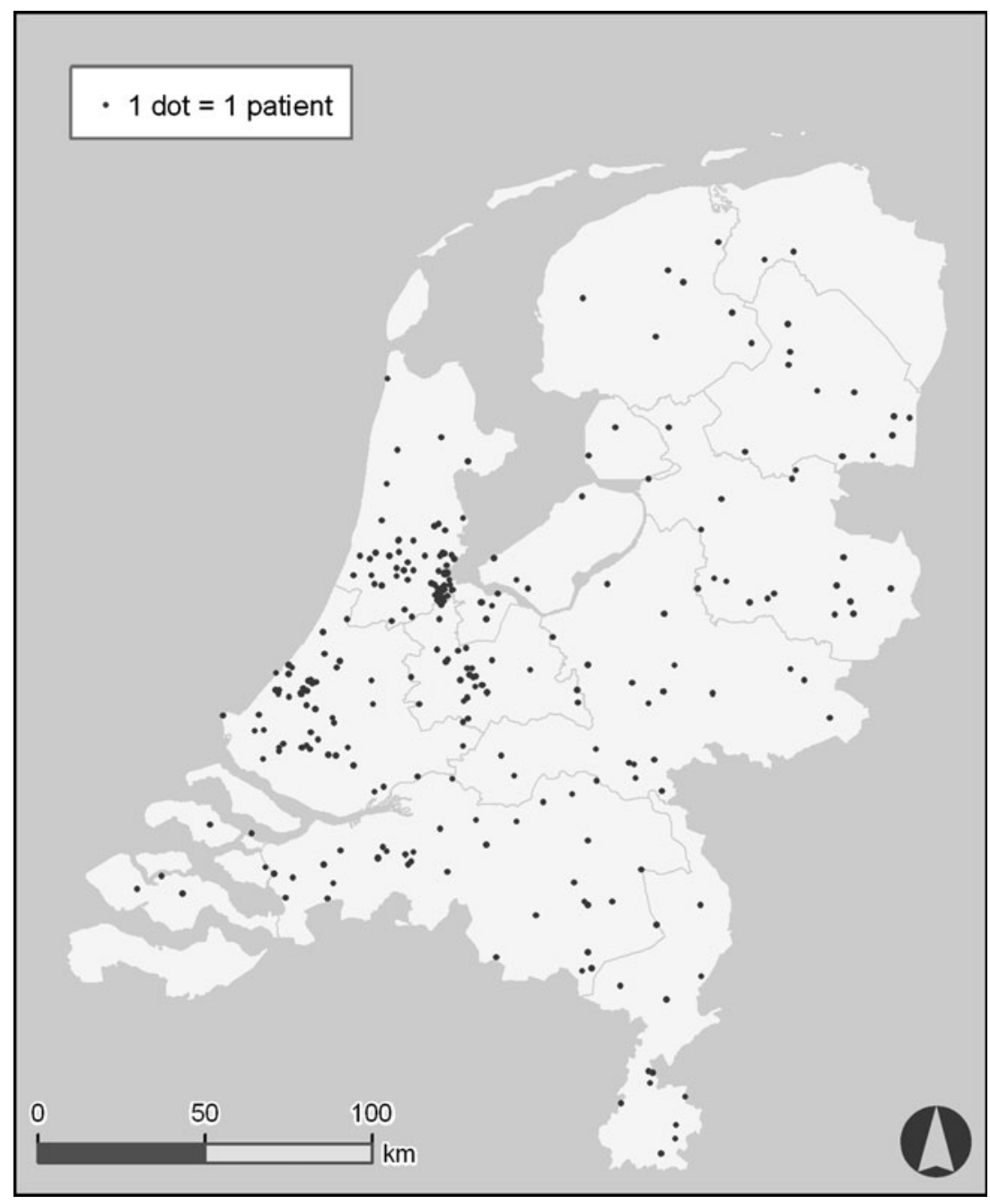

\section{Discussion}

The articles found in the literature review relate mostly to retrospective studies from around the world (Table 1). They describe different populations, backgrounds and a large variability in genetics. All these factors influence the comparability.

Historic retrospective study dates are reported from 1946 onwards (Erie County, OH, USA) till 1998 (Yorkshire, UK) [5-13]. From the three prospective studies, one was from France (1985-1992) (Bouissou et al. ESPN 1993) and the other two from New Zealand and Australia in 1998-2004 (Table 1) $[3,14]$. The retrospective articles merely studied a hospital population or part of the population in a city, region, county or several districts. Thus, results from a wide variety of populations make them difficult to compare. A retrospective incidence in different age groups was reported as 1.8-11.6:100,000 patients/year [5-13]. The two more recent prospective population studies in New Zealand and Australia were quite similar to the one in The Netherlands, and they also used the Paediatric Surveillance Unit to register all new cases of NS $[3,14]$. To our knowledge, the Dutch study is the largest and longest prospective study so far.

We registered all children with NS in The Netherlands for 4 years. The NSCK shows a response rate of $92.75 \%$ [4]. Beyond that, we extensively explored possible nonregistered cases by regular announcements, personal telephone calls and e-mail contacts with nearly all Dutch paediatricians. We believe that we have registered all children with newly diagnosed NS in The Netherlands, so defining a reliable incidence. The three prospective studies revealed an incidence of $1.15-2.1$ per 100,000 [3, 14] children per year, which was comparable with the Dutch incidence of 1.52 per 100,000 children per year in 20032006. In contrast to the studies in Australia [3] and France (Bouissou et al, ESPN 1993), our Dutch population showed a higher male preponderance, whereas the study in New Zealand [13] showed an even higher male:female ratio (2.5:1). In comparison with the retrospective studies the 
male:female ratio of 2.04:1 is similar to the ones found in the study by Schlesinger et al. in Erie County, OH, [8] and Wyatt et al. in the eastern part of Kentucky in the United States [11]. The other studies show a lower male:female ratio $[5-7,9,10,12,13]$. Even if the older children ( $>15$ years) were left out, compared with the registration in Australia [14], this predominance still existed. In the general population in The Netherlands, the male:female ratio is $1.05: 1$, and in Australia this ratio is also 1.05:1; thus, this does not explain the difference between the two countries. Wong et al. do not explain why they think that the ratio found in their study differs from the rest of the studies [14]. We do not have a thorough explanation for the difference in male:female ratio between the studies. Boyer et al. [15] described that patients with FSGS were older at diagnosis and that the female gender was slightly overrepresented in comparison with children with another aetiology of NS. In our study, the male predominance was present in nearly all age groups.

The definition of NS was similar in all studies in relation to symptoms and laboratory findings. However, the inclusion criteria of ethnic background and age were not comparable. Our registry included all children aged from 0 to 18 years. After we completed the database, children with congenital NS were excluded because of the difference in pathogenesis. During the 4 years of registration, four children with congenital NS were excluded. According to this registration, the incidence of CNS in The Netherlands was one child with CNS per year. Exclusion of CNS is the reason that some studies started registration from 3 months onwards.

Wong et al. [13], Srivastata et al. [10] and McKinney et al. [7] reported a median age of, respectively, 4.5, 5.0, 4.5 (SSNS) and 6.0 (SRNS) years; mean age differed from 3.4 to 7.4 years $[7,10,13]$. Some studies did not mention a median or mean age. The median age found in our study was 3.9 years and is lower than the ones found in the reviewed literature, where mean age appeared to be 5.1 years. Due to the fact that some ethnic groups seem to be more prone to developing FSGS (e.g. African American and Indian children) rather than MCNS [16], retrospective studies might be biased, because they are mostly based on medical charts in one centre or region of a country. In our prospective study, a question about the ethnic background was not included. Ethnicity will be explored in a follow-up study planned to begin soon. Some paediatricians spontaneously mentioned the ethnicity of their patient in the questionnaire. For 32 patients, ethnicity is not known $(14 \%)$. With the gathered information in the questionnaires so far and the informed consent forms, we were able to divide the rest of the patients into Western and non-Western ethnic group. The majority of patients $(60.1 \%)$ were of Dutch nationality (from western origin). The non-Western patients $(25.9 \%)$ came from a wide variety of countries divided over all continents.

The mortality rate in this study is preliminary because it only shows the number of patients who died at presentation. To our knowledge, other series do not report mortality at presentation. This means that NS is still a serious disease, even at presentation. Two other authors published mortality rates, but all in earlier years, and were not comparable with idiopathic NS as stated in the definition $[8,13]$.

In conclusion, our study showed an incidence in the same range as the few other prospective studies. Idiopathic NS in children in the Dutch population is as much a rare disease as in any other country in the world. We found a statistically significant male:female ratio in this study, which is not fully explained but is in line with one other prospective study that described a similar or even higher male:female ratio in their cohort. Given the rarity of the disease and the lack of understanding of the exact pathogenesis of NS in children, more research is needed, preferably done in international collaboration studies.

Acknowledgements This registry was performed by the NSCK and the working group Idiopathic Nephrotic Syndrome in The Netherlands. We thank Mrs. A. Lambinon from NSCK for administrative support and all the members of the working group for their comments and intellectual support. The Dutch Kidney Foundation (Nierstichting) has partly funded this project (project number KP-01). Our gratitude goes to all paediatricians who reported patients with NS to the NSCK and to the patients and their parents for their participation. We also thank Nancy Omtzigt and Alfred Wagtendonk for making the geographic map representing the distribution of patients with NS in The Netherlands (Fig. 1).

Conflict of interest statement We declare no conflicts of interest.

Open Access This article is distributed under the terms of the Creative Commons Attribution Noncommercial License which permits any noncommercial use, distribution, and reproduction in any medium, provided the original author(s) and source are credited.

\section{Reference}

1. Chesney RW (1999) The idiopathic nephrotic syndrome. Curr Opin Pediatr 11(2):158-161

2. Filler G (2003) Treatment of nephrotic syndrome in children and controlled trials. Nephrol Dial Transplant 18(Suppl 6):vi75-vi78

3. Hodson E, Craig J, Willis N (2002) Congenital and idiopathic nephrotic syndrome. In: Elliott E (ed) Ninth Annual Report Australian Paediatric Surveillance Unit. Snap Printing, Parramatta, pp 6-8

4. Rodrigues Pereira R (2003) Jaarverslag Nederlands Signaleringscentrum Kindergeneeskunde. 2003.

5. Elzouki AY, Amin F, Jaiswal OP (1984) Primary nephrotic syndrome in Arab children. Arch Dis Child 59(3):253-255

6. Feehally J, Kendell NP, Swift PGF, Walls J (1985) High incidence of minimal change nephrotic syndrome in Asians. Arch Dis Child 60(11):1018-1020 
7. McKinney PA, Feltbower RG, Brocklebank JT, Fitzpatrick MM (2001) Time trends and ethnic patterns of childhood nephrotic syndrome in Yorkshire, UK. Pediatr Nephrol 16(12):1040-1044

8. Schlesinger ER, Sultz HA, Mosher WE, Feldman JG (1968) The nephrotic syndrome. Its incidence and implications for the community. Am J Dis Child 116(6):623-632

9. Sharples PM, Poulton J, White RH (1985) Steroid responsive nephrotic syndrome is more common in Asians. Arch Dis Child 60(11):1014-1017

10. Srivastava T, Simon SD, Alon US (1999) High incidence of focal segmental glomerulosclerosis in nephrotic syndrome of childhood. Pediatr Nephrol 13(1):13-18

11. Wyatt RJ, Marx MB, Kazee M, Holland NH (1982) Current estimates of the incidence of steroid responsive idiopathic nephrosis in Kentucky children 1-9 years of age. Int J Pediatr Nephrol 3(2):63-65
12. Zaki M, Helin I, Manandhar DS, Hunt MCJ, Khalil AF (1989) Primary nephrotic syndrome in Arab children in Kuwait. Pediatr Nephrol 3(2):218-220

13. Rothenberg MB, Heymann W (1957) The incidence of the nephrotic syndrome in children. Pediatrics 19(3):446-452

14. Wong W (2007) Idiopathic nephrotic syndrome in New Zealand children, demographic, clinical features, initial management and outcome after twelve-month follow-up: Results of a three-year national surveillance study. J Paediatr Child Health 43(5):337-341

15. Boyer O, Moulder JK, Somers MJ (2007) Focal and segmental glomerulosclerosis in children: a longitudinal assessment. Pediatr Nephrol 22(8):1159-1166

16. Filler G, Young E, Geier P, Carpenter B, Drukker A, Feber J (2003) Is there really an increase in non-minimal change nephrotic syndrome in children? Am J Kidney Dis 42:1107-1113 